\title{
Static and Seismic Performance of Buried Pipelines: A review
}

\author{
Dhuha F. Yousife ${ }^{1, a}$, Asad H. Aldefae ${ }^{1, b^{*}}$, Salah L. Zubaidi 1,c , Wissam H. Humaish ${ }^{2, d}$ \\ and Evgeny K. Sinichenko,e \\ ${ }^{1}$ Civil Engineering Department, Wasit University, Wasit, Iraq. \\ ${ }^{2}$ Hydraulic and Engineering Hydrology, Peoples' Friendship University (RUDN), Russia.

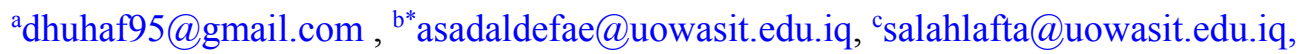 \\ dwhumaish@uowasit.edu.iq, ${ }^{\mathrm{e}} \mathrm{c}$ (sinichenko-ek@rudn.ru
}

\begin{abstract}
Today, buried pipes can be considered one of the main substantial infrastructures which has significant role with human life. Such projects serve purposes, including, drain lines, water mains, sewage lines, telephone and electrical conduits, highway and railway culverts, gas and liquidpetroleum lines, coal slurry lines, subway tunnels and various other special functions. This paper focuses on reviewing, describing and understanding the static and dynamic behavior of underground pipes during earthquake events and at rest condition involving seismic vulnerability causes, failure modes of pipelines and loads subjected on pipes. A quick glance on the assisting factors that reduce the pipes breakage due to earthquakes is presented. Also, this paper reviews some previous studies about performance of underground pipes under seismic loads. It was concluded that the soil density has a significant impact on the displacements corresponding to the maximum force. For shallow pipes to obtain the minimum lateral displacement value, it is recommended to use soil density medium to dense state. It was observed also there is a relationship between the spacing of pipes and its displacement so; to obtain the minimum displacement the spacing between the pipes must be at least equal to the pipe diameter.
\end{abstract}

Keywords: Buried pipes; earthquake; seismic loads; liquefaction; failure mode.

\section{Introduction}

To raise the human lifestyle due to increasing of the population, pipelines below ground surface were utilized many decades ago. Now days underground surface pipelines provide in extensive extent of request like drinking water pipes, sewer/drain lines, electrical/telephone services, lines of oil, also channel, lines of coal slurry, as well as newly lines of heat distribution, tunnels of subway [1]. Protection of buried pipelines, consider one of the greatest extreme part of vital citified structures that the requests of design depending on in the working of buried pipelines which expose to various loading situations. The protection of pipes as a goal cannot be achieved unless their actual performance is well known and taken into account [2]. One of the well-inspected failure mechanisms in pipelines the once that was happened during south central Alaska earthquake in 2002 [3]. See Fig. 1.

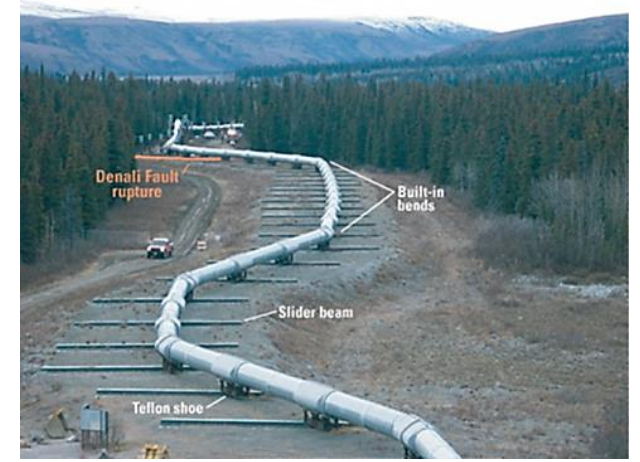

Figure 1. Oil pipe failure due to south central Alaska earthquake [3].

This paper focuses on reviewing the basic information about the dynamic performance and response of underground pipelines. First of all, the introduction describes the main previous 
researches concerning with the main topic of the paper then, the first part describes determination of pipeline's seismic vulnerability causes, loads on buried pipes and pipeline's failure modes. Finally, several previous studies including experimental and numerical tests.

\section{The Previous Main Findings}

Many studies were performed on large and small scale buried pipelines using many physical modeling techniques like geotechnical centrifuge under N-g level [2,4], under 1-g level using shaking table tests [5] and using finite element method [6,7]. Experimental tests have been performed using the dynamic centrifuge model to estimate the uplift behaviors of shallow-constructed pipe in liquefied zones and susceptible to seismic shaking [4]. Through the response of the earth surface and pore pressures near the pipe, the uplifting mechanism was discussed. Furthermore, the analysis process of load, which the pipes were exposed to during and before the shaking, was found. By comparing the calculated with the measured results, one can notice that the load analysis was reasonable. The pipe's uplifting performance was the composite impact of multifarious loads; it was largely governed by the value of the excess pore water pressure. The behavior of a big-diameter underground pipeline was examined with particular focus on the soil liquefaction-subject flotation stability [2,9]. For a summation of eight experiments of shaking table performed on an underground pipeline in a laminar box under a gravitational field of $30 \mathrm{~g}$, centrifugal modeling technique was used where the results are presented. The ground was prepared at a relative density of $38 \%$ with Nevada sand and shaken at amplitude of $0.5 \mathrm{~g}$ with a sinusoidal wave. The use of a viscous fluid fulfilled the relations of time scaling for both dissipation and dynamic phenomena in a stratum of fully saturated soil. As the soil liquefied, the centrifugal modeling technique simulated pipeline flotation. To mitigate flotation, a method that depends on gravel and geo-synthetic substances was studied. The soil behavior was studied under the action of excess pore water pressure and acceleration.

The pipe uplift, ground surface's deformation, and response of earth pressure were investigated as well. Due to the obtained results from many studies [10-12]. A design method was suggested for the underground pipeline to provide a sufficient flotation resistance caused by liquefaction of soil. The stiffness and dead load of the gravel that confined geo-synthetically were important elements in the design. Furthermore, the findings provided in the present research are beneficial for validation of numerical methods, depending on which parametric researches could be performed. The occurrence probability of the liquefaction due to earthquake that effect directly on the seismic failure of pipelines in a saturated sand deposit may be largely minimized if the sand became little unsaturated [13]. Denitrifying bacteria are used in this study to create small, inert bubbles of $\mathrm{N}_{2}$ within the sand layers. Several experiments of shaking table have been performed using a laminar box for the saturated deposit of sand and sand strata that contain bubbles of bacteriologically produced $\mathrm{N}_{2}$. The obtained results of this study showed that for the second model, the obtained pore pressure was significantly lower than that of the first test. Thus, the suggested approach was efficient in the reduction of the liquefaction potential of the sand.

In order to evaluate the manner of underground pipelines installation in liquefiable layers, a linked stress-flow technique of finite element was used depending on the equations of dynamic biotechnology. Describing of the dominant equations, constitutive models of the soil, discretization of finite elements have been presented. The obtained results were compared with the tests of soil deposit's dynamic centrifuge test and the pipeline performed at practical acceleration of $30 \mathrm{~g}$. The pore pressure, acceleration, the pipe uplift, and earth pressure, were studied in details. The obtained analysis's results showed that the analysis of the pipe's and soil's dynamic behavior up to the stage of the liquefaction stage is possible using a linked finite element method of stress-flow as the deposit was expressed by Pastor-Zienkiewicz Mark model. The response behaviors of the soil foundations' excess pore pressure, and also the efficacy of various samples of reinforcement of drainage measures by the method of finite element have been investigated [14]. The numerical model of a coupled stressflow of finite element depends on the u-p formula of Biot's dynamic models [15]. In numerical model, the hyperbolic relationship of strain and stress was depended; it takes into account the degradation of 
strength and stiffness. Development of the pore pressure resulting from the loading of earthquake wave by the model of pore pressure was calculated [16].

Numerical models' accuracy was investigated by the simulation of shake table experiments. The collected data from the pore pressure transducers during the experiments was considered as a reference to check the accuracy of the numerically determined excess pore pressures. The efficacy of various measures of drainage against the uplifting of the pipeline was also compared. The models had the ability to produce results in line with tests. The performance of buried pipes was studied experimentally; a physical model of steel buried pipe trench statement is developed under cyclic loading condition [17]. The steel flexible model pipes were used and placed inside a soil trench of medium silica sand within the tested box and raining technique with three various relative densities have been considered. Earth pressure transducers and pore water pressure transducers were installed around the pipes. In the trench the depth of the pipes was changed and the cyclic loads of various amplitudes were subjected to the surface of trench centrally and accentually. Comparisons were performed also for the data of field tests with the expected responses of soil pressures around and above the pipes, deformed cross-sectional pipe profiles and pipe deflections. The results of the field test showed well output without any apparent opening of the joint or structural distress. They concluded the buried pipe behavior was largely affected by the methods of backfilling and external force. The results showed that the system's the failure mechanism and deflection performance are largely depend on the depth of the embedment, the density of soil, the amplitude of the load, and the eccentricity of the load. In the dense soil the failure of the soil-pipe system occurred for the depth of embedment below 1.5D due to high deflections of the loading plate and pipe together. For the safe design and performance of buried pipes in dense soils, above mentioned depth is equal to (2D) can be recommended as the minimum required depth.

The pipe connections' influence on the deformation of the joint (JDs) of underground segmented pipes is studied by [18]. Various factors, such as pipe diameter, shapes of the connection, conditions of the ground, seismic incident angles, input ground movements, and angles of the branch have been considered in this study. The findings presented that the JDs of segmented pipes can be decreased about $40 \%-50 \%$ by pipe connections. Investigational tests to determine the buried pipeline's response to the lateral displacement of ground caused by respective movement between the pipelines and soil surrounding it are conducted by [19]. The lateral loading test's force-displacement results revealed that the soil density has a significant impact on the displacements corresponding to the maximum force. 3D numerical modeling on single- and double-embedded pipelines in order to assess the effects of pipeline spacing and burial depth on the pipe response when subjected to horizontal load is investigated [19]. After the installation of a single pipeline, it was discovered that the greatest horizontal displacement occurs at a burial depth equal to the pipe diameter. With different burial depths of $1.05 \mathrm{~m}, 2.1 \mathrm{~m}$, and $4.2 \mathrm{~m}$, a single pipe with $0.015 \mathrm{~m}$ thickness and $2.1 \mathrm{~m}$ diameter was considered (i.e., equal to half a diameter, one diameter, and two times the diameter, respectively). The maximum displacement estimated in the pipe's centerline is between $0.015 \mathrm{~m}$ and $0.018 \mathrm{~m}$. The maximum value of displacement is obtained when the spacing is half the pipe diameter, while the minimum value is obtained when the spacing is equal to the pipe diameter.

The transverse response of buried UPVC pipes subjected to transverse earthquake shake is assessed [20]. The analysis was carried out using a valid finite element model. The impact diameter of pipe, height of backfill, maximum acceleration ground, backfill weight, rock layer location, and frequency of the earthquake predominant motion are considered. The findings revealed that an earthquake increases thrust of pipe wall, bending moment of pipe wall, and change of vertical diameter. The findings also revealed that increasing height of backfill or maximum acceleration ground significantly improves the buried pipe's earthquake response. Furthermore, it was discovered that the backfill's weight soil has no bearing on the pipe's earthquake response. On the other hand, the position of the earthquake shake seems to have a significant effect on the pipe's seismic response. 


\section{Determination of Pipeline's Seismic Vulnerability Causes}

It is important to have clear definitions for the major causes of the seismic vulnerability to minimize the seismic response effect of pipelines. The followings are several significant reasons of pipeline's seismic vulnerability [21].

Wave Propagation. The distance to the seismic center, the quantity of the released energy, the wave type, the soil type in the area of the wave propagation and the region's topography governs the period and intensity of the waves that propagate through earthquakes. During the wave propagation, energy transfers to the over ground and underground constructions like pipelines. Underground pipelines may be undergoing the transfer of displacements during wave propagation.

Ground's Permanent Displacements. The resulted seismic waves are able to create a permanent displacement in location and restrictions. The seismic displacement can be considered one of the major causes to the failure of the pipeline systems that built over ground and even underground during an earthquake. The failure is categorized to uplift, liquefaction faulting, and landslide [21].

Uplift. It is normally generated by vertical component of ground movement. Uplift has the greatest harmful influences on both outlets and inlets (flanges and attachments).

Liquefaction. It occurs due to soil transformation to a liquid from a solid condition because successful strengthening of soil stress becomes marginal or zero by earthquake motion of high frequency, and thus, soil does not carry the applied shear stresses, typically as liquid does. In the soils of small cohesion, at the case of relatively raised ground water elevation, liquefaction is expected to occur. This phenomenon can cause the emergence of underground equipment and the sinking of aboveground equipment. Probability of occurrence of liquefaction and its severity enhances as the duration of earthquake increases.

Faulting. It occurs at the ground or the crust of the earth surface. It can subject severe desolation effects to the pipe line system as they are susceptible to the acceleration less than displacement (and even speed). It may be horizontal or vertical or an inclined.

Landslide. The movement of ground is able to transmit enormous soil quantities in hills even without liquefaction, if it is linked to moisture, strength, slope of the soil, and consolidation ratio. Probability of landslide is an indication for the earthquake duration and severity. It is able to stop access ways and creates serious deterioration for both underground and over ground systems of pipeline. Fig. 2 shows the landslides induced pipelines failure [22].
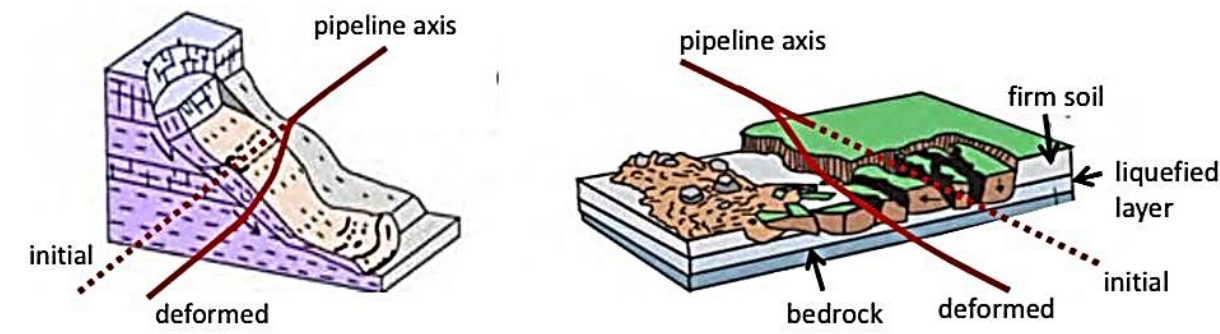

Figure 2. Diagram of pipeline configuration at liquefaction induced lateral spreading (right) and landslide boundary (left) [22].

\section{Pipelines' Failure Modes}

Pipes exposed to seismic loads during earthquake generally lose their stability because of their yield (i.e., the axial strains exceed the design limit). The failure modes of pipes differ according to the pipe type (if it is segmented or continuous). Due to the results of the major occurred earthquakes, it is possible to describe the failure modes of pipeline by the following points [23]: 
(i) For the continuous underground pipes, the dominant failure domes include the failure due to tension, buckling (whether it is beam or local), and welding.

(i) For the segmented underground pipes, axial pullout, flanged joint failure, rotation of joints, smashing of bell-and-spigot joints, and circumferential failure are considered the dominant modes of failure

\section{Continuous Buried Pipelines. The failure odes can be classified into:}

Tensile Failure. Each of the earthquake risks such as lateral diffusion, faulting, landslides, as well as liquefaction, may be subjected the pipeline below tension also eventually contribute with the growth of large tensile strain to the pipeline, leading to the failure as a result tensile. There are several earthquake risks, landslide consider the major reason of failure tension for pipeline. Tension strain of pipeline will increase for the degree of rupture a portion network of pipeline [23].

Buckling Failure. A pipeline's buckling failure may be indicated to such pipe unbalanced during seismic shaking due to extreme forces axial compressive. There may be two forms of buckling: beam buckling and local buckling. Because of unbalanced of local for the wall of pipe local buckling occurs which also known as compressional wrinkling. Both propagability of wave and earth distortion try to focus on those crinkles as soon as wrinkles start to occur. For that reason, local bending becomes so high in the walls of pipe that it contributes to the pipe wall's circumferential cracking or tearing, and probably leading to leakage and rupture. Fatigue cracks can grow in the buckled area at the highest strain concentration region, which can seriously be threat the safety of constructional of pipeline [20]. Fig. 3 demonstrates an example of a failure of the pipeline due to beam buckling and local buckling.
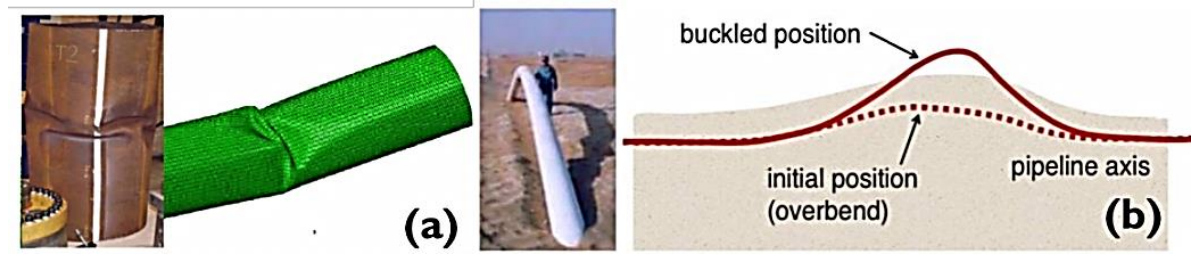

Figure 3. (a) Excessive pipe wall compression causes local when the pipe is bent longitudinally and (b) Excessive axial loading causes buckling beam for buried pipeline [22].

Welding Failure. In general, the failure of pipelines in the time of earthquake because of unsafe linking between pipe's pieces has become so much common. The possible reason for failure is in the welding failure in which the old pipeline, the efficiency of connections is very weak. In comparison, connections have large efficiency in newer pipelines as well as they have not a significant reason for failure in the current period, since they are pre-made also examined before being laid for strength as well as durability. This form of strength was not received by older pipelines, which may be a potential explanation for welded connection failures in the pipeline network. Furthermore, they added together related steel pipeline by high efficiency connections have behave satisfied, until with subjected to wide various earth motions [23].

Fatigue Failure. Due to repeated loading during earthquakes, pipelines typically fail by fatigue. The fatigue cracks may develop from shallow depths to the deepest, making the pipe leaks or ruptures. The essential failures modes in the pipe due to Nihonkai-Chubu earthquake in 1983 are reported by [24]. The failure modes were because of recurrent tensile and compressive loads, and rarely each failure modes can be caused by the static tensile load created by a very high permanent ground movement. When the soil is displaced post the hit of an earthquake wave, deformation due to bending on the pipe's straight parts noticeably show beam buckling failure. Furthermore, the tensile fracture occurred in the heat-affected welding zone, indicate that the pipe was underwent to tensile stresses and frequent pressure [23].

Segmented Buried Pipelines. During earthquakes, joints are most vulnerable in separate pipelines. The axial root out at joints is being the most popular way of failure for separated pipeline as one of 
failure mechanism. Disconnected of joints, happens in the zones of tension earth strain. Some examples of axial root out of separate pipeline are illustrated in Figure 4.
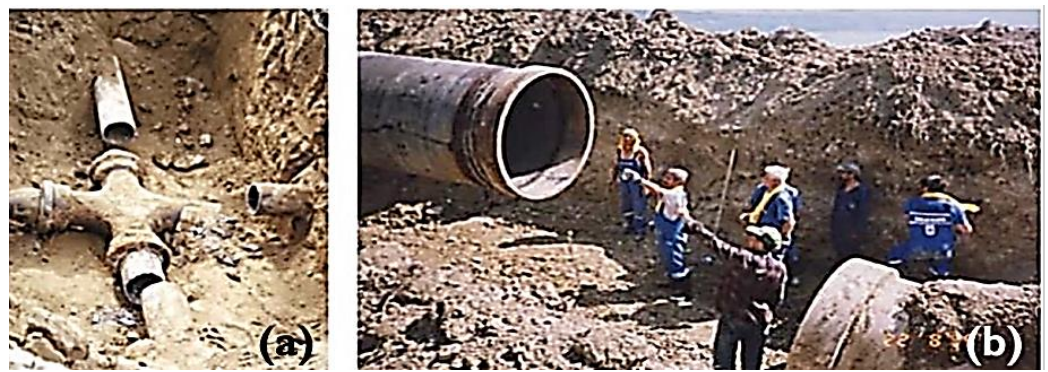

Figure 4. Failure pipelines modes because of mechanical joint root out in the (a) 2011 Christchurch seismic; as well as (b) Tohoku 2011 [23].

In addition to the axial pullout, the failure of flanged joint, which happens because of fracture connection of flange, is a different pipelines' failure mode found in the previous earthquakes as display in Fig.5, several cases of pipeline failures because of failure flanged joint failure.
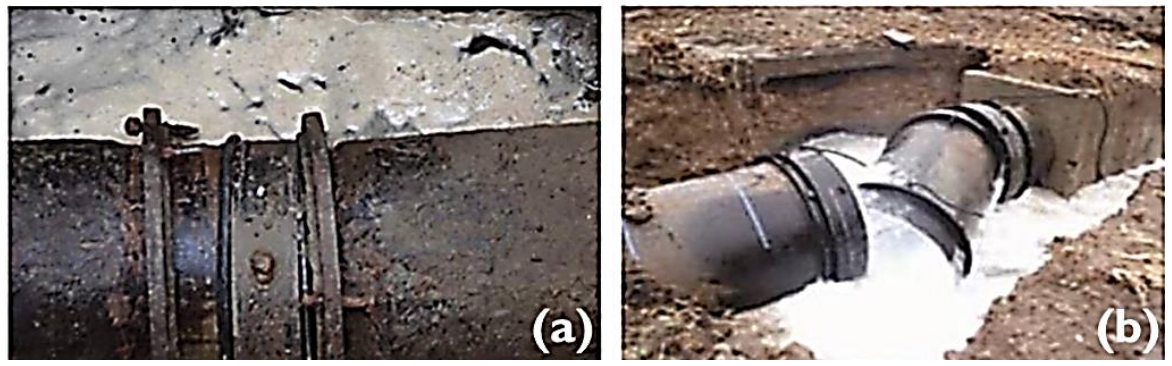

Figure 5. Failure pipelines modes because of mechanical joint root out in the (a) 2011 Christchurch seismic; as well as (b) Tohoku 2011 [23].

On the contrary, spigot joints as well as crushing of bell are the popular way of separated pipeline failure in the zones of compressive strain as shown in Fig. 6. Such failure mode leads to the production of cracks, squeeze and fracture of pipelines at shearing its joint and joints at the dyad or farther.
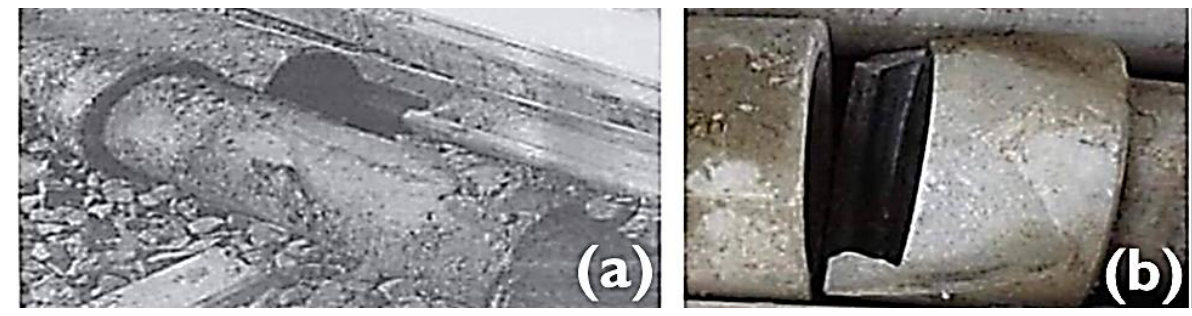

Figure 6. Cast-iron pipe's failure because of-spigot joints and crushing of bell in the 2001 Gujarat earthquake [23].

\section{Loads on Buried Pipes}

In addition to the internal fluid pressure, the pipe buried underground must withstand other loads. Soil overload, groundwater, surface forces subjected on the ground surface involving the vehicular load, and loads due to seismic movement must be assisted. Thus, the underground pipes system is a structure and it can be considered a fluid conveyor conduit. That being the case, to ensure that both duties are fulfilled, special design procedures are required [25].

Overburden Stress. The normal forces borne by the pipeline involves a soil block that stretches along the edges of the block from the surface of the soil to the pipe's highest edge, minus (or plus) shear stresses. If the soil prism above a pipeline or the soil around that prism relatively settles, the shear forces are developed. For example, relative to the surrounding soil, the prism of soil over the pipeline in an excavated ditch will settle. This settlement will be resisted by the shear force between 
the original soil and the backfill, thereby reducing the prism's load carried by the pipeline [25]. The common formula used to calculation the overburden stresses transmitted to the pipeline, which developed by this group is shown in Eq. 1 .

$\mathrm{Wc}=\mathrm{C} \omega \mathrm{B}^{2}$

Where Wc represent the entire force per length unit of the pipe, $C$ is coefficient of load that depends on the soil kind, fill or trench, rates of relative settlement rates for the pipeline and the surrounding layers, and type of installation, $\omega$ represents the unit weight of the soil layers that carried by pipeline, and B is the trench's width of the pipe's external diameter. In design manual steel pipe for the American Water Works Association (AWWA) [26], it was purposed the total of burden stress over an underground pipe made of steel supposed equal to a prism of soil layers of a width equivalent to the external diameter of the pipeline and height equivalent to the backfill depth (see Eq. 2).

$\mathrm{Wc}=\omega \mathrm{Bch}$

Where $\mathrm{Bc}$ the outer diameter of the pipe and $\mathrm{h}$ is representing soil depth from the surface to the pipe's top.

Surcharges at Grade. The buried pipelines usually carry sustain load types subjected to the surface plus the weight of the backfill soil. These loads are usually generated the weight for the passing vehicles over the path of the pipe. Furthermore, buried pipes are also affected by stationary objects applied, above the pipeline or around it [25].

Live Loads. Various wheeled traffic, which comes from the vehicles of highway, airplane, and railroad engines, is the key cause of designing live loads on buried pipes. Stresses subjected on underground structures by the standard truck loading of HS-20 [27] and the rail loading of Cooper E80 were assessed for different cover depths depending on the solution of Boussinesq and an appropriate engineering judgment, they are obtainable in various shapes in a variety of publications $[28,29]$. It is typically appropriate to analyze each case separately because of the large variance in wheel loading of airplanes and heavy trucks. Fig. 7 shows the typical design criterion of piplelines.

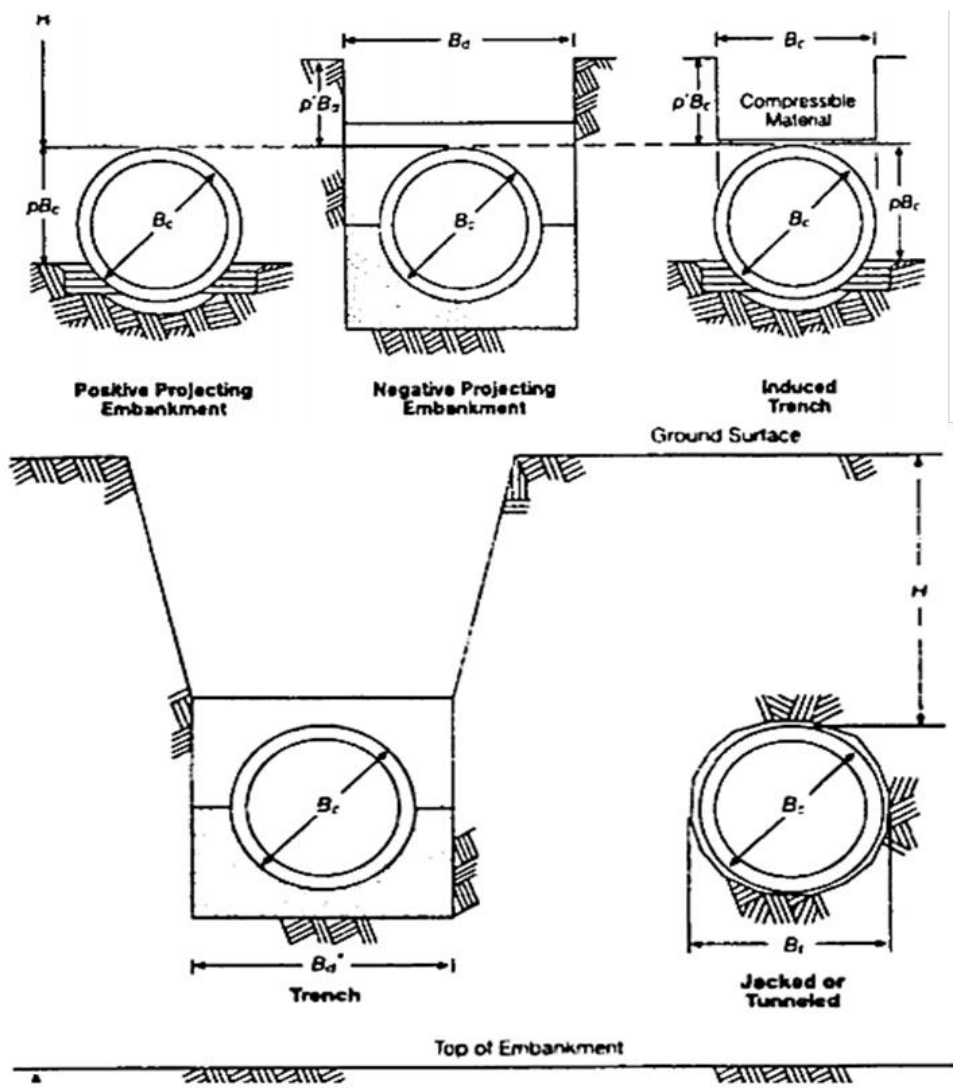

Figure 7. Typical underground pipe installations [25]. 
Seismic Loads. Underground pipes are usually designed to carry the applied stresses due to the ground movements in areas of high seismicity. Procedures for evaluation have been developed by American Society of Civil Engineers (ASCE) to determine the magnitude of axial and flexural strains caused by seismic motions in underground lines [30]. Generally, the loads in the wall of pipe as a result of seismic motion-induced strains in pipe walls are very small and did not play an essential rule in the design adversely. As main design specifications permit for an enhancement in permissible stress or a decrement in factors of load, buried pipes that designed to withstand other loads typically are able to carry the seismic loads if they are involved in combination of the loads. Fig. 8 shows the seismic forces of embedded pipeline.

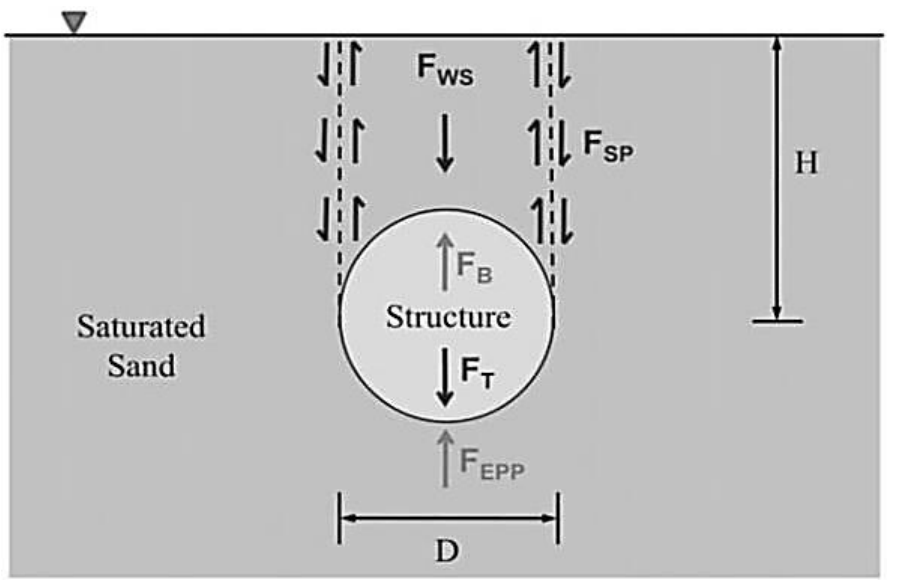

Figure 8. Force showing on a pipe in liquefied soil [12].

\section{Conclusions}

This paper presents the basic principles for understanding the static and seismic behavior of underground pipelines in term of mechanism of failure and its causes. The conclusions are:

- It was concluded that the displacement of pipes is greatly affected by the density of soil. Also, the spacing between pipes should be at least equal to the diameter of pipe to obtain minimum displacement. The embedded depth of structure below the ground surface effects on the horizontal displacement.

- The causes of seismic weakness are wave propagation and the permanent displacement of the earth that includes uplift, landslide, faulting and liquefaction.

- Direction of the earthquake plays an important role in the failure mode of the pipelines. The pipes lose their stability during an earthquake due to their exposure to seismic loads that leads to (the axial strains exceed the design limit).

- The failure modes of the pipes differ according to the type of pipe if it is continuous or in the form of separate pipes.

- Direction of the earthquake plays an important role in the failure mode of the pipelines.

- The buried underground pipes must be able to withstand other loads such as (overburden loads, seismic loads, live loads and surcharge at grade loads) in additional internal pressure of the fluid.

\section{Reference}

[1] Moser, A.P. and Folkman, S., 2008. Buried pipe design. McGraw-Hill Education.

[2] Ling, H.I., Mohri, Y., Kawabata, T., Liu, H., Burke, C. and Sun, L., 2003. Centrifugal modeling of seismic behavior of large-diameter pipe in liquefiable soil. Journal of geotechnical and geoenvironmental engineering, 129(12), pp.1092-1101.

[3] US Department of the Interior, US Geological Survey, 2003. Rupture in South-central Alaska: The Denali Fault Earthquake of 2002. 
[4] Huang, B., Liu, J., Ling, D. and Zhou, Y., 2015. Application of particle image velocimetry (PIV) in the study of uplift mechanisms of pipe buried in medium dense sand. Journal of Civil Structural Health Monitoring, 5(5), pp.599-614.

[5] Tafreshi, S.M. and Khalaj, O., 2008. Laboratory tests of small-diameter HDPE pipes buried in reinforced sand under repeated-load. Geotextiles and Geomembranes, 26(2), pp.145-163.

[6] Magda, W., 1997. Wave-induced uplift force on a submarine pipeline buried in a compressible seabed. Ocean Engineering, 24(6), pp.551-576.

[7] Ling, H.I., Sun, L., Liu, H., Mohri, Y. and Kawabata, T., 2008. Finite element analysis of pipe buried in saturated soil deposit subject to earthquake loading. Journal of earthquake and Tsunami, 2(01), pp.1-17.

[8] Bao, X., Jin, Z., Cui, H., Chen, X. and Xie, X., 2019. Soil liquefaction mitigation in geotechnical engineering: An overview of recently developed methods. Soil Dynamics and Earthquake Engineering, 120, pp.273-291.

[9] Zhang, Z.M., Xin, G.F., Wu, Q.Y., Wang, N.X. and Zeng, Y.J., 2006. Centrifuge model tests on super-long piles with large diameters considering mudcake effect [J]. Chinese Journal of Geotechnical Engineering, 12.

[10] O'Rourke, T.D., Jung, J.K. and Argyrou, C., 2016. Underground pipeline response to earthquake-induced ground deformation. Soil Dynamics and Earthquake Engineering, 91, pp.272-283.

[11] O'Rourke, M.J. and Liu, X., 1999. Response of buried pipelines subject to earthquake effects (p. 260). New York: Mceer.

[12] Chian, S.C., Tokimatsu, K. and Madabhushi, S.P.G., 2014. Soil liquefaction-induced uplift of underground structures: Physical and numerical modeling. Journal of Geotechnical and Geoenvironmental Engineering, 140(10), p.04014057.

[13] He, J., Chu, J. and Ivanov, V., 2014. Mitigation of liquefaction of saturated sand using biogas. In Bio-and Chemo-Mechanical Processes in Geotechnical Engineering: Géotechnique Symposium in Print 2013 (pp. 116-124). ICE Publishing.

[14]Zou, D., Kong, X. and Xu, B., 2007. Numerical Simulation of Seimic Behavior of Pipeline in Liquefiable Soil. In Soil Stress-Strain Behavior: Measurement, Modeling and Analysis (pp. 673682). Springer, Dordrecht

[15]Zienkiewicz, O.C., 1982. Basic formulation of static and dynamic behaviour of soil and other porous media. In Numerical methods in geomechanics (pp. 39-55). Springer, Dordrecht.

[16] Seed, H.B., Martin, P.P. and Lysmer, J., 1976. Pore-water pressure changes during soil liquefaction. Journal of the geotechnical engineering division, 102(4), pp.323-346.

[17] Teja, A.S., 2018, February. Field investigation on structural performance of the buried UPVC pipes with and without geogrid reinforcement. In AIP Conference Proceedings (Vol. 1930, No. 1, p. 020035). AIP Publishing LLC.

[18] Liu, W., Song, Z. and Wang, Y., 2020. Seismic Analysis of the Connections of Buried Segmented Pipes. Computer Modeling in Engineering \& Sciences, 123(1), pp.257-282.

[19] Castiglia, M., Fierro, T. and Santucci de Magistris, F., 2020. Pipeline performances under earthquake-induced soil liquefaction: state of the art on real observations, model tests, and numerical simulations. Shock and Vibration, 2020.

[20] Alzabeebee, S., 2019. Response of buried uPVC pipes subjected to earthquake shake. Innovative Infrastructure Solutions, 4(1), pp.1-14.

[21] Manshoori, M.R., 2011. Evaluation of seismic vulnerability and failure modes for pipelines. Procedia Engineering, 14, pp.3042-3049.

[22] Karamanos, S.A., Keil, B. and Card, R.J., 2014. Seismic design of buried steel water pipelines. In Pipelines 2014: From Underground to the Forefront of Innovation and Sustainability (pp. 1005-1019).

[23] Nair, G.S., Dash, S.R. and Mondal, G., 2018. Review of pipeline performance during earthquakes since 1906. Journal of Performance of Constructed Facilities, 32(6), p.04018083. 
[24] Nishio, N., Tsukamoto, K. and Hamura, A., 1987. Model experiment on the strain in buried pipeline associated with soil liquefaction (pp. 141-157). Amsterdam, Netherlands: Elsevier.

[25] Doyleand, J. M. and Fang, S. J., 1999. Underground Pipe. Structural Engineering Handbook Ed. Chen Wai-Fah Boca Raton: CRC Press LLC.

[26] American Water Works Association,1989. Steel Pipe-A Guide for Design and Installation: M1 1

[27] American Association of State Highway and Transportation Officials (AASHTO). Standard Specifications for Highway Bridges. 1992, 15th ed.

[28] American Society for Testing and Materials (ASTM), A796, 1994. Standard practice for structural design of corrugated steel pipe, pipe-arches and arches for storm and sanitary sewers and other buried applications.

[29] American Water Works Association,1995. Concrete Pressure Pipe: M9 (Vol. 9).

[30] Committee on Seismic Analysis of the ASCE Structural Division Committee on Nuclear Structures and Materials, 1983. Seismic Response of Buried Pipes and Structural Components. American Society of Civil Engineers (ASCE). 